\title{
Combined Effects of Temperature and Salinity on Colonies of Botryllus schlosseri and Botrylloides leachi (Ascidiacea) from the Venetian Lagoon
}

\author{
R. Brunetti ${ }^{1}$, L. Beghi ${ }^{2}$, M. Bressan ${ }^{3}$ and M. G. Marin ${ }^{3}$ \\ ${ }^{1}$ Istituto di Biologia Animale, Università di Padova, via Loredan 10, I-35100 Padova, Italy \\ ${ }^{2}$ Seminario Matematico, Università di Padova, via Belzoni 7, I-35100 Padova, Italy \\ ${ }^{3}$ Stazione Idrobiologica, Università di Padova, via Canali 3, I-30015 Chioggia, Italy
}

\begin{abstract}
Combined effects of temperature and salinity on colonies of Botryllus schlosseri and Botrylloides leachi from the Venetian Lagoon have been studied in two series of experimental samples, consisting respectively of 'young' colonies (from oozoid to 5th blastogenetic generation) and 'adult' colonies (from 5th to 9th blastogenetic generation), at several combinations of temperature (from $3^{\circ}$ to $28{ }^{\circ} \mathrm{C}$ ) and salinity (from $16 \%$ to $44 \%$ S). In both series percentage of survival, index of colonial growth, index of quality of life and mean length of zooids at the end of treatment have been calculated and processed in order to obtain response surfaces. B. leachi is less eurytherm and less euryhaline than $B$. schlosseri; however, the former exhibits a higher regulative capacity. Colonial growth does not differ noticeably between young and adult colonies in $B$. leachi; in $B$. schlosseri growth is much higher in young colonies than in adult ones. Generally, adult colonies of $B$. schlosseri exhibit a greater range of tolerance to experimental conditions than young ones; the opposite is true for $B$. leachi.
\end{abstract}

\section{INTRODUCTION}

The life cycles of the Botryllinae of the Venetian Lagoon, Botryllus schlosseri (Pallas) and Botrylloides leachi (Savigny), have been studied by Sabbadin (1955a) and Brunetti $(1974,1976)$. There is a noticeable difference in the length of their sexual reproduction periods and in their colonial behaviour during winter. The distributions of the two species in the Venetian Lagoon seldom overlap (Brunetti and Menin, 1977). All these facts seem to imply a clear difference between $B$. schlosseri and $B$. leach $i$ in their tolerance to temperature and salinity. In this paper we examine the combined effects of these environmental factors on the two species at different stages of their colonial life.

The combined effects of temperature and salinity on marine invertebrates and fishes have been reviewed extensively in 'Marine Ecology', Volume I (Brett, 1970; Garside, 1970; Kinne, 1970, 1971; Holliday, 1971; Alderdice, 1972).

\section{MATERIAL AND METHODS}

Botrylloides leachi differs from Botryllus schlosseri in its gonad arrangement, larval incubation, structure of the common cloacal chamber and some other morphological aspects related to the digestive tube (Brunetti, 1979). In spite of these differences both species are very similiar and present the same bilateral budding (Berrill, 1941, 1947); hence it is possible to adopt for both the colonial staging proposed by Berrill (1941) and Sabbadin (1955b) for B. schlosseri. All buds develop synchronously and at a given stage of their development they replace their parents, which are reabsorbed by the colonial vascular system. In this process, called 'change of generation' some buds could be reabsorbed together with their parent, thus the total number of zooids of a colony can either increase, remain constant or decrease.

Two series of experiments have been performed, the first one on colonies developing from zero generation (oozoid) to the 5th, and the second one on colonies from the 5 th to 9 th generation (with a few exceptions). We labelled the two series as 'young' and 'adult' colonies, respectively. The series of young colonies consisted of 23 samples each with 20 colonies, kept at different combinations of temperatures $\left(11^{\circ} \mathrm{C}, 16^{\circ} \mathrm{C}, 18^{\circ} \mathrm{C}\right.$, $\left.22{ }^{\circ} \mathrm{C}, 26^{\circ} \mathrm{C}\right)$ and salinities $(20 \%, 24 \%, 33 \%, 38 \%$, $44 \% \mathrm{~S}$ ). The series of adult colonies consisted of 20 samples, kept at combinations of $3{ }^{\circ} \mathrm{C}, 10^{\circ} \mathrm{C}, 18^{\circ} \mathrm{C}$, $24{ }^{\circ} \mathrm{C}, 28{ }^{\circ} \mathrm{C}$ versus $16 \%, 24 \%, 38 \%, 44 \% \mathrm{~S}$. 
Both series of samples were obtained on glass slabs by metamorphosis of larvae spontaneously generated from adult colonies collected in the Lagoon. Adult colonies reached the 5th blastogenetic generation in aquaria with continuous water flow at $18^{\circ} \mathrm{C} \pm 1 \mathrm{C}^{\circ}$ and salinity between 30 and $35 \% \mathrm{~S}$. The colonies were brought to experimental conditions by gradual adjustment of temperature and salinity over a period of $12 \mathrm{~h}$. During the experiment they were placed in thermostated containers with 31 of sea water kept in constant motion by an aerator. Salinity was adjusted by addition of artificial hyperaline sea water or of distilled water. The food consisted of a mixture of Phaeodactylum tricornutum, Dunaliella sp. and Chlorella sp. Water and food were renewed daily.

In order to evaluate the influence of different combinations of temperature and salinity and to determine the area of optimal conditions, we adopted the method of the 'response surfaces' (Box, 1954; Box and Youle, 1955; see also Alderdice, 1972), applying it to the parameters: percentage of survival, index of colonial growth, index of 'quality of life', mean length of zooids (young colonies only).

Percentage of survival. This is the ratio between number of surviving colonies of a given sample at the end of the observation period and total number of colonies of the sample at the beginning of treatment.

Index of colonial growth. The growth of colonies number of adult zooids at different blastogenetic generations) is difficult to study because of its great variability under identical environmental conditions (Brunetti and Copello, 1978). In the present paper we estimate growth by means of the ratio $[x(m)-x(n)] / x(n)$, where $x(n), x(m)$ are the number of adult zooids constituting the colony at the blastogenetic generations $n, m,(n<m) ; n$ and $m$ are the same for all colonies examined. The experimental treatment lasted for 5 blastogenetic generations (i.e. $m-n=5$ ); the time span was different for the different samples because of the dependence of the rate of development of the buds on temperature (Sabbadin, 1955b).

Index of quality of life. This stems from non-quantitative observations and is based on quantification of so-called 'soft data' (Feinstein, 1975). We chose 9 categories characterizing the quality of life of the colony. To each of them we attributed a positive score and one or more negative ones, according to a scale based on our research experience. The positive score refers to normal conditions; its value ranges from 1 to 9: the normal character which disappears first in case of unfavourable environmental conditions is attributed the maximum value; a character which can be alterated only in case of worse conditions gets a lower score. The negative scores refer to various degrees of abnormality.

On both positive and negative scores a scale shift has been successively performed (adding +9 ) in order to obtain only non-negative values. The $k$-vectors of numerical variables so obtained $(k=9)$ have been finally combined into a single value, by summing all components of the $k$-vector and by dividing the result by the sum of all maximum positive values that can be attributed to the different variables. This ratio, between 0 and 1, constitues the index of quality of life of the colony. The categories chosen are:

(A) B lastogenetic formula. According to Berrill (1941) and Sabbadin (1955b) we considered as normal every situation that could be expressed by one of the following stages: 9-7-1,9-8-2, 9-8-3, . . $9-8-6,11-9-7-1$. We considered as abnormal stages such as $9-6,11-5,11-8, \ldots$

(B) Feeding.

(C) Circulatory system. The zooids of the colony are interconnected by means of a vascular network which, in Botryllus schlosseri, shows welldefined characters (Brunetti and Burighel, 1969; Mukai et al., 1978). We considered as anomalous every situation where the vessels connecting the zooids were collapsed or absent.

(D) Tunic. The Botryllinae tunic is transparent under normal conditions. We consequently considered as abnormal an opaque, wrinkled, scarcely elastic tunic.
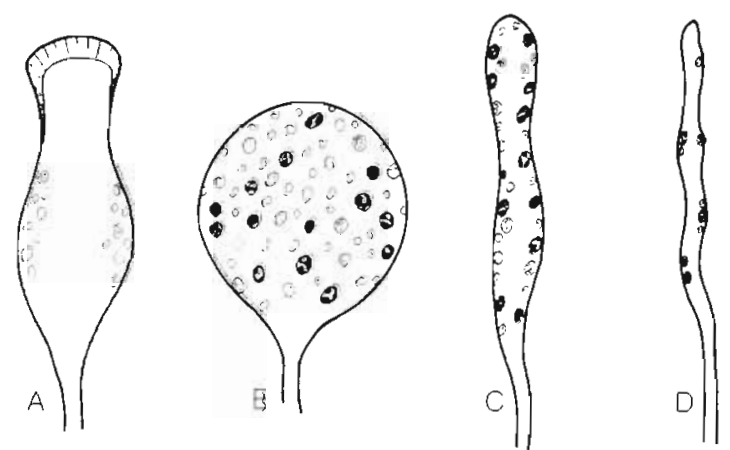

Fig. 1. Botryllus schlosseri and Botrylloides leachi. Morphological aspects of ampullae. A: normal (bottle-shāped); B: spherical; C: spindle-shaped; D: atrophic

(E) Morphology of ampullae. We refer to the ampullae of the marginal vessel. They usually have bottle form (Fig. 1 A). We considered as abnormal other possible morphological aspects (Fig. 1 B-D).

(F) Pigmentation. Normally the pigmentation of the colony, due to blood cells, allows observation of internal structures by transparence; only during the change of generation is this not true because of the increased number of phagocytes. We termed spread pigmentation the abnormal presence of such a situa- 
tion during the whole period between two successive changes of generation.

(G) Arrangement of zooids in systems.
(H) Cardia c contractions. We evaluated the efficiency of cardiac contractions by examining their effect on the blood flow.

Table 1. Categories referring to quality of life

\begin{tabular}{|c|c|c|c|}
\hline Categories & Aspects of categories & Scores & Transformed scores \\
\hline \multirow[t]{2}{*}{ A blastogenetic formula } & normal & +7 & 16 \\
\hline & abnormal & -3 & 6 \\
\hline \multirow[t]{3}{*}{ B feeding } & normal & +8 & 17 \\
\hline & scarce & -2 & 7 \\
\hline & no food & -6 & 3 \\
\hline \multirow[t]{2}{*}{ C circulatory system } & normal & +6 & 15 \\
\hline & abnormal & -5 & 4 \\
\hline \multirow[t]{2}{*}{$\mathrm{D}$ tunic } & transparent & +5 & 14 \\
\hline & opaque & -4 & 5 \\
\hline \multirow[t]{4}{*}{ E ampullae } & bottle-shaped & +9 & 18 \\
\hline & spherical & -3 & 6 \\
\hline & spindle-shaped & -3.5 & 5.5 \\
\hline & atrophic & -4 & 5 \\
\hline \multirow{2}{*}{ F pigmentation } & normal & +6 & 15 \\
\hline & spread & -4 & 5 \\
\hline \multirow[t]{2}{*}{ G arrangement of zooids in systems } & present & +4 & 13 \\
\hline & absent & -8 & 1 \\
\hline \multirow[t]{4}{*}{$\mathrm{H}$ cardiac contractions } & normal & +3 & 12 \\
\hline & not too efficient & -6 & 3 \\
\hline & endocardiac vibrations only & -8 & 1 \\
\hline & absent & -9 & 0 \\
\hline \multirow[t]{2}{*}{ I general aspect of colony } & normal & +3 & 12 \\
\hline & swollen & -7 & 2 \\
\hline
\end{tabular}

Table 2. Botryllus schlosseri. Survival of young colonies under different experimental conditions

\begin{tabular}{|c|c|c|c|c|c|c|}
\hline & \multicolumn{5}{|c|}{ Temperature $\left({ }^{\circ} \mathrm{C}\right)$} & \multirow[t]{2}{*}{ Salinity $(\%)$} \\
\hline & 11 & 16 & 18 & 22 & 26 & \\
\hline $\mathrm{N}^{\circ}$ of colonies & & & 16 & 16 & 16 & \multirow{5}{*}{20} \\
\hline Days of treatment & & & 36 & 29 & 27 & \\
\hline Colonial growth & & & present & present & present & \\
\hline Mortality $(\%)$ & & & 6.25 & 18.75 & 31.25 & \\
\hline Degeneration $(\%)$ & & & 0 & 0 & 0 & \\
\hline$N^{\circ}$ of colonies & 17 & 16 & 16 & 16 & 16 & \multirow{5}{*}{24} \\
\hline Days of treatment & 77 & 44 & 36 & 27 & 21 & \\
\hline Colonial growth & present & present & present & present & present & \\
\hline Mortality $(\%)$ & 12 & 6.25 & 0 & 0 & 0 & \\
\hline Degeneration $(\%)$ & 0 & 0 & 0 & 0 & 0 & \\
\hline $\mathrm{N}^{\circ}$ of colonies & 16 & 16 & 16 & 16 & 16 & \multirow{5}{*}{33} \\
\hline Days of treatment & 55 & 41 & 36 & 26 & 21 & \\
\hline Colonial growth & present & present & present & present & present & \\
\hline Mortality $(\%)$ & 0 & 0 & 0 & 0 & 0 & \\
\hline Degeneration $(\%)$ & 6.25 & 0 & 0 & 0 & 0 & \\
\hline $\mathrm{N}^{\circ}$ of colonies & 16 & 15 & 17 & 16 & 16 & \multirow{5}{*}{38} \\
\hline Days of treatment & 70 & 44 & 38 & 26 & 21 & \\
\hline Colonial growth & present & present & present & present & present & \\
\hline Mortality $(\%)$ & 6.25 & 0 & 0 & 0 & 0 & \\
\hline Degeneration $(\%)$ & 6.25 & 0 & 0 & 0 & 0 & \\
\hline$N^{\circ}$ of colonies & 16 & 16 & 16 & 16 & 16 & \multirow{5}{*}{44} \\
\hline Days of treatment & 56 & 44 & 41 & 29 & 23 & \\
\hline Colonial growth & absent & present & present & present & present & \\
\hline Mortality $(\%)$ & 12.5 & 43.75 & 0 & 37.5 & 6.25 & \\
\hline Degeneration $(\%)$ & 62.5 & 0 & 0 & 0 & 12.5 & \\
\hline
\end{tabular}


(I) General aspect of the colony. The tunic is normally compact, but in certain abnormal conditions it can present hollows filled with water.

The scores assigned to the different variables are listed in Table 1.

Interaction between quality-of-life categories, as well as dependence of the latter on temperature and salinity have been estimated by means of the squared canonical correlation (Williams, 1952; Anderberg, 1973). For better estimation of interaction between categories, colonies showing all normal characters, as well as degenerated and dead ones, have been omitted. With the same purpose, temperature and salinity have been considered as variables with no rank ordering.

Length of zooids (young colonies only). Measurements were performed, at the end of the treatment, on the ventral portion of the zooids adhering to the support by Botryllus schlosseri, and on the projections of the endostyles on the support by Botrylloides leachi.

\section{RESULTS}

\section{Morphological Observations}

Botryllus schlosseri. The results of the treatment of experimental samples are summarized in Tables 2 and 3. By 'degeneration' we mean a process of irreversible regression of the colony that involves at first the adult zooids and successively the buds, turning the colony into a chaotic bulk of vessels and ampullae, without the possibility of recognizing any zooid structure by observation 'in vivo'. The colony can last in such a state for a long time before dying.

Another interesting phenomenon was exhibited by the colonies at $16 \% \mathrm{~S}$ : a strong alteration in bud growth preceded colonial degeneration, with the exception of colonies kept at $24^{\circ} \mathrm{C}$; some buds kept at $18^{\circ} \mathrm{C}$ were able to reach the adult stage, but they showed a structural simplification (reduction in number of oral tentacles and in number of rows of stygma with respect to the parental zooids).

Botrylloides leachi. The situation after treatment is summarized in Tables 4 and 5 . Under certain environmental conditions the colonies underwent hibernation. Other colonies exhibited a different type of reaction which we called 'colonial regression', similar in certain aspects to hibernation, but distinct from it.

Hibernation (Burighel et al,, 1976) consists of a regression of zooids and buds with exception of those in Stage 3, which stop their development. At the same time ampullae proliferate and cover the regressing structures and the remaining buds.

By 'colonial regression' we mean the regressing of adult zooids, while their buds continue in their development for a certain time and finally regress without having opened their syphons. At the moment of their regression the presence of a new generation is

Table 3. Botryllus schlosseri. Survival of adult colonies under different experimental conditions

\begin{tabular}{|c|c|c|c|c|c|c|}
\hline & \multicolumn{5}{|c|}{ Temperature $\left({ }^{\circ} \mathrm{C}\right)$} & \multirow[t]{2}{*}{ Salinity $(\% \circ)$} \\
\hline & 3 & 10 & 18 & 24 & 28 & \\
\hline $\mathrm{N}^{\circ}$ of colonies & 21 & 20 & 19 & 20 & 21 & \\
\hline Days of treatment & 13 & 30 & 15 & 18 & 15 & \\
\hline Colonial growth & absent & absent & present & present & absent & 16 \\
\hline Mortality $(\%)$ & 100 & 5 & 0 & 0 & 50 & \\
\hline Degeneration $(\%)$ & 0 & 95 & 16 & 0 & 45 & \\
\hline $\mathrm{N}^{\circ}$ of colonies & 22 & 21 & 24 & 20 & 20 & \\
\hline Days of treatment & 11 & 46 & 25 & 18 & 15 & \\
\hline Colonial growth & absent & present & present & present & present & 24 \\
\hline Mortality $(\%)$ & 100 & 0 & 0 & 0 & 0 & \\
\hline Degeneration $(\%)$ & 0 & 0 & 0 & 0 & 0 & \\
\hline $\mathrm{N}^{\circ}$ of colonies & 21 & 19 & 20 & 20 & 20 & \\
\hline Days of treatment & 11 & 46 & 26 & 18 & 14 & \\
\hline Colonial growth & absent ${ }^{\circ}$ & present & present & present & present & 38 \\
\hline Mortality $(\%)$ & 20 & 0 & 0 & 0 & 0 & \\
\hline Degeneration $(\%)$ & 0 & 0 & 0 & 0 & 0 & \\
\hline$N^{0}$ of colonies & 20 & 19 & 20 & 20 & 19 & \\
\hline Days of treatment & 13 & 46 & 26 & 18 & 11 & \\
\hline Colonial growth & absent ${ }^{\circ}$ & present & present & present & present & 44 \\
\hline Mortality (\%) & 80 & 0 & 0 & 0 & 0 & \\
\hline Degeneration $(\%)$ & 0 & 0 & 0 & 0 & 0 & \\
\hline
\end{tabular}


Table 4. Botrylloides leachi. Survival of young colonies under different experimental conditions

\begin{tabular}{|c|c|c|c|c|c|c|}
\hline & \multicolumn{5}{|c|}{ Temperature $\left({ }^{\circ} \mathrm{C}\right)$} & \multirow[t]{2}{*}{ Salinity $(\%)$} \\
\hline & 11 & 16 & 18 & 22 & 26 & \\
\hline $\mathrm{N}^{\circ}$ of colonies & \multicolumn{5}{|c|}{16} & \multirow{5}{*}{20} \\
\hline Days of treatment & & & 18 & & & \\
\hline Colonial growth & & & absent & & & \\
\hline Mortality $(\%)$ & & & 44 & & & \\
\hline Colonial regression $(\%)$ & & & 56 & & & \\
\hline $\mathrm{N}^{\circ}$ of colonies & 16 & 16 & 16 & 16 & 16 & \multirow{5}{*}{24} \\
\hline Days of treatment & 18 & 26 & 29 & 26 & 10 & \\
\hline Colonial growth & absent & absent & absent & present & absent & \\
\hline Mortality $(\%)$ & 50 & 31 & 6 & 0 & 0 & \\
\hline Colonial regression $(" / \%)$ & 50 & 69 & 12 & 12.5 & 94 & \\
\hline $\mathrm{N}^{\circ}$ of colonies & 16 & 16 & 15 & 16 & 15 & \multirow{5}{*}{33} \\
\hline Days of treatment & 43 & 43 & 32 & 26 & 26 & \\
\hline Colonial growth & absent & present & present & present & present & \\
\hline Mortality $(\%)$ & 0 & 0 & 0 & 0 & 0 & \\
\hline Colonial regression $(\%)$ & 12.5 & 0 & 0 & 0 & 0 & \\
\hline $\mathrm{N}^{\circ}$ of colonies & 16 & 16 & 16 & 15 & 16 & \multirow{5}{*}{38} \\
\hline Days of treatment & 46 & 46 & 39 & 26 & 19 & \\
\hline Colonial growth & absent & present & present & present & present & \\
\hline Mortality $(\%)$ & 0 & 0 & 0 & 0 & 0 & \\
\hline Colonial regression $(\%)$ & 25 & 0 & 0 & 0 & 0 & \\
\hline $\mathrm{N}^{\circ}$ of colonies & 16 & 16 & 16 & 16 & 16 & \multirow{5}{*}{44} \\
\hline Days of treatment & 18 & 26 & 18 & 19 & 10 & \\
\hline Colonial growth & absent & absent & absent & absent & absent & \\
\hline Mortality $(\%)$ & 0 & 0 & 6 & 6 & 0 & \\
\hline Colonial regression $(\%)$ & 100 & 25 & 81 & 50 & 94 & \\
\hline
\end{tabular}

Table 5. Botrylloides leachi. Survival of adult colonies under different experimental conditions

\begin{tabular}{|c|c|c|c|c|c|c|}
\hline & \multicolumn{5}{|c|}{ Temperature $\left({ }^{\circ} \mathrm{C}\right)$} & \multirow{2}{*}{ Salinity $(\%)$} \\
\hline & 3 & 10 & 18 & 24 & 28 & \\
\hline $\mathrm{N}^{\circ}$ of colonies & 20 & 20 & 20 & 20 & 20 & \\
\hline Days of treatment & 1 & 1 & 1 & 1 & 1 & \\
\hline Colonial growth & absent & absent & absent & absent & absent & 16 \\
\hline Mortality $(\%)$ & 100 & 100 & 100 & 100 & 100 & \\
\hline Colonial regression $(\%)$ & 0 & 0 & 0 & 0 & 0 & \\
\hline Hibernation $(\%)$ & 0 & 0 & 0 & 0 & 0 & \\
\hline $\mathrm{N}^{\circ}$ of colonies & 20 & 20 & 19 & 20 & 18 & \\
\hline Days of treatment & 7 & 12 & 22 & 16 & 16 & \\
\hline Colonial growth & absent & absent & present & present & present & 24 \\
\hline Mortality $(\%)$ & 0 & 20 & 0 & 0 & 0 & \\
\hline Colonial regression $(\%)$ & 0 & 0 & 0 & 0 & 0 & \\
\hline Hibernation $(\%)$ & 0 & 80 & 0 & 0 & 11.1 & \\
\hline $\mathrm{N}^{\circ}$ of colonies & & & 22 & 20 & 23 & \\
\hline Days of treatment & & & 23 & 23 & 15 & \\
\hline Colonial growth & & & present & present & present & 30 \\
\hline Mortality $(\%)$ & & & 0 & 0 & 0 & \\
\hline Colonial regression $(\%)$ & & & 0 & 0 & 0 & \\
\hline Hibernation $(\%)$ & & & 0 & 0 & 0 & \\
\hline $\mathrm{N}^{\circ}$ of colonies & 21 & 12 & 20 & 20 & 19 & \\
\hline Days of treatment & 7 & 31 & 24 & 16 & 20 & \\
\hline Colonial growth & absent & absent & present & present & present & 38 \\
\hline Mortality $(\%)$ & 0 & 0 & 0 & 0 & 0 & \\
\hline Colonial regression $(\%)$ & 0 & 0 & 0 & 5 & 10.5 & \\
\hline Hibernation $(\%)$ & 0 & 0 & 0 & 0 & 0 & \\
\hline $\mathrm{N}^{\circ}$ of colonies & 21 & 21 & 19 & 20 & 20 & \\
\hline Days of treatment & 7 & 17 & 15 & 16 & 10 & \\
\hline Colonial growth & absent & absent & absent & absent & absent & 44 \\
\hline Mortality $(\%)$ & 0 & 0 & 0 & 0 & 0 & \\
\hline Colonial regression $(\%)$ & 0 & 0 & 100 & 100 & 100 & \\
\hline Hibernation & 0 & 100 & 0 & 0 & 0 & \\
\hline
\end{tabular}


noticeable (presumably in Stage 3); it follows the fate of the previous generation.

Colonial regression differs, therefore, from hibernation in the following aspects: (1) Regression involves many successive blastogenetic generations at consecutive times, without the opening of the syphons; (2) the youngest generation does not stop its development at Stage $3 ;(3)$ ampullae never proliferate.

Both processes are reversible, after reversing the environmental conditions. An example of colonial regression and recovery is shown in Figure 2.

At $3{ }^{\circ} \mathrm{C}$, all colonies stopped growth at the change-
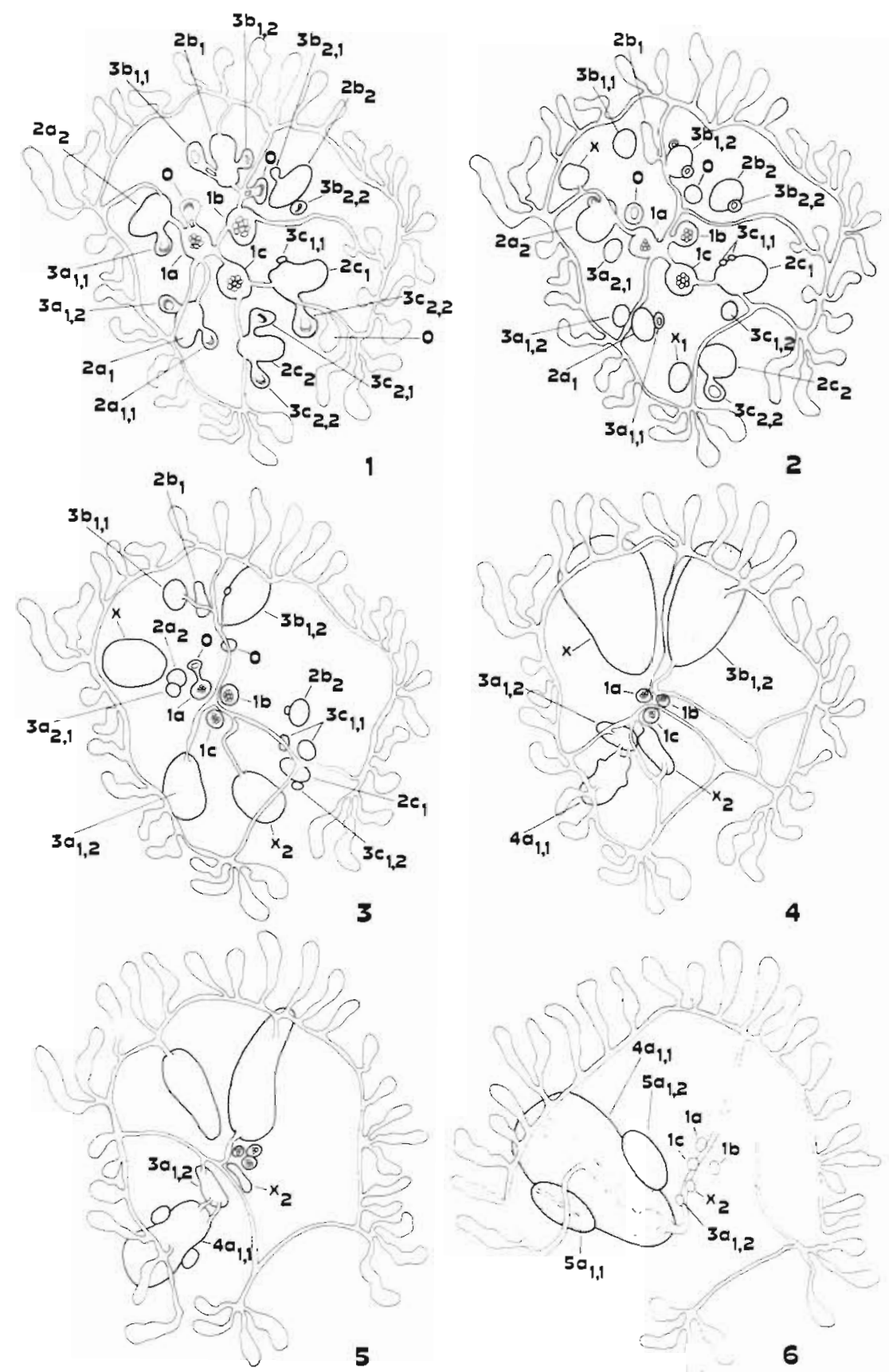

4

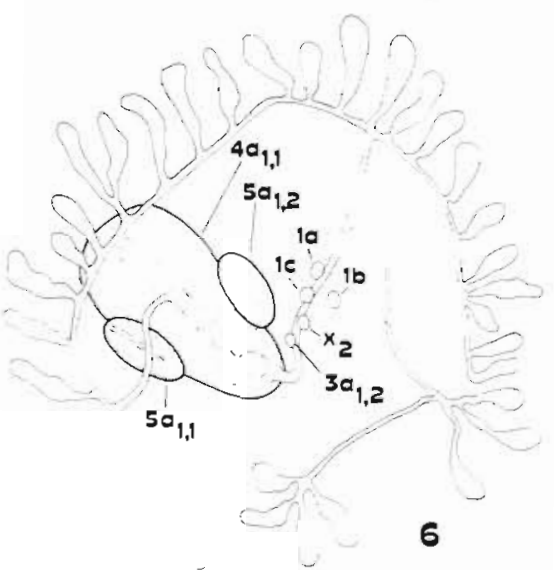

Fig. 2. Botrylloides leachi. Example of regression and subsequent recovering of a colony $\left(18{ }^{\circ} \mathrm{C} ; 44 \%\right.$ S $) .1: \mathrm{July} 10 ; 2: J u l y ~ 13 ; 3:$ July $15 ;$ in all cases no adult zooid. End of treatment and restoration of breeding conditions. 4: July 20 ; 5 ; July 22 ; no adult zooid. 6: July 25; zooid $4 \mathrm{a}_{1,2}$ manifests filter-feeding activity. Small numbers 0,1 etc: different blastogenetic zooid generations. Letters genealogy of buds. Subscript numbers: position of bud with respect to parental zooid (1. right; 2 : left). Symbols $\times, x_{1}, x_{2}$ : structures of uncertain origin (vascular buds?) having initially the aspect of spherical ampullae. $1 \mathrm{a}, 1 \mathrm{~b}$ and $1 \mathrm{c}$ : zooid residuals preceding colonial regression 


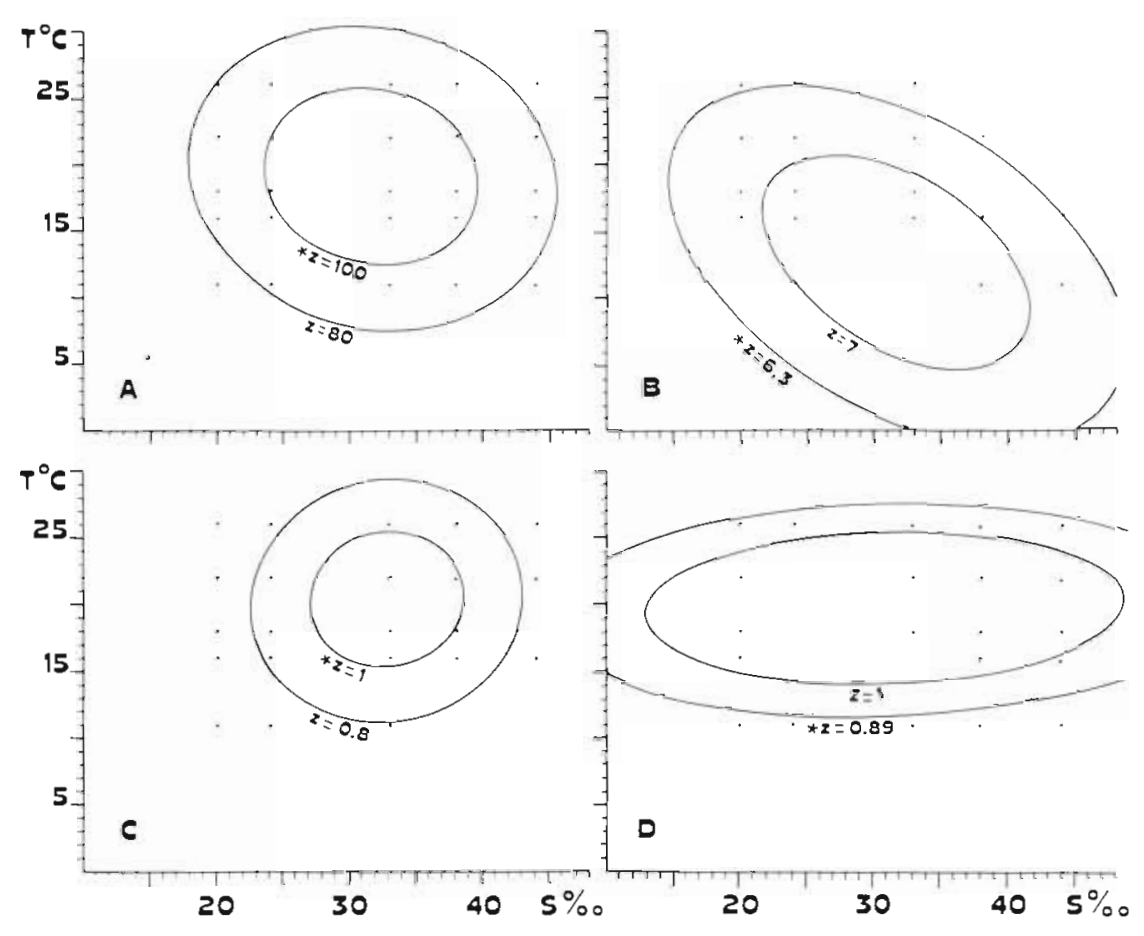

Fig. 3. Botryllus schlosseri. Response surfaces for young colonies. A: Percentage of survival $\left(z=\sin ^{2}-2.731+0.147 T+0.188 \mathrm{~S}\right.$ $\left.-0.003 T^{2}-0.003 S^{2}-0.0006 T S ; F_{5 / 22}=1.44\right)$. B: Index of colonial growth $\left(z=-11.56+0.87 T+0.88 S-0.02 T^{2}-0.01 S^{2}-\right.$ $\left.0.01 T S ; F_{5 / 297}=378\right)$. C: Index of quality of life $\left(z=-3.08+0.12 T+0.18 S-0.003 T^{2}-0.003 S^{2}+0.0004 T S ; F_{5 / 377}+120.8\right)$. D: Mean length $(\mathrm{mm})$ of zooids $\left(z=-0.45+0.13 T+0.02 S-0.003 T^{2}-0.0003 S^{2}+0.0002 T S ; F_{5 / 247}=272.9\right)$

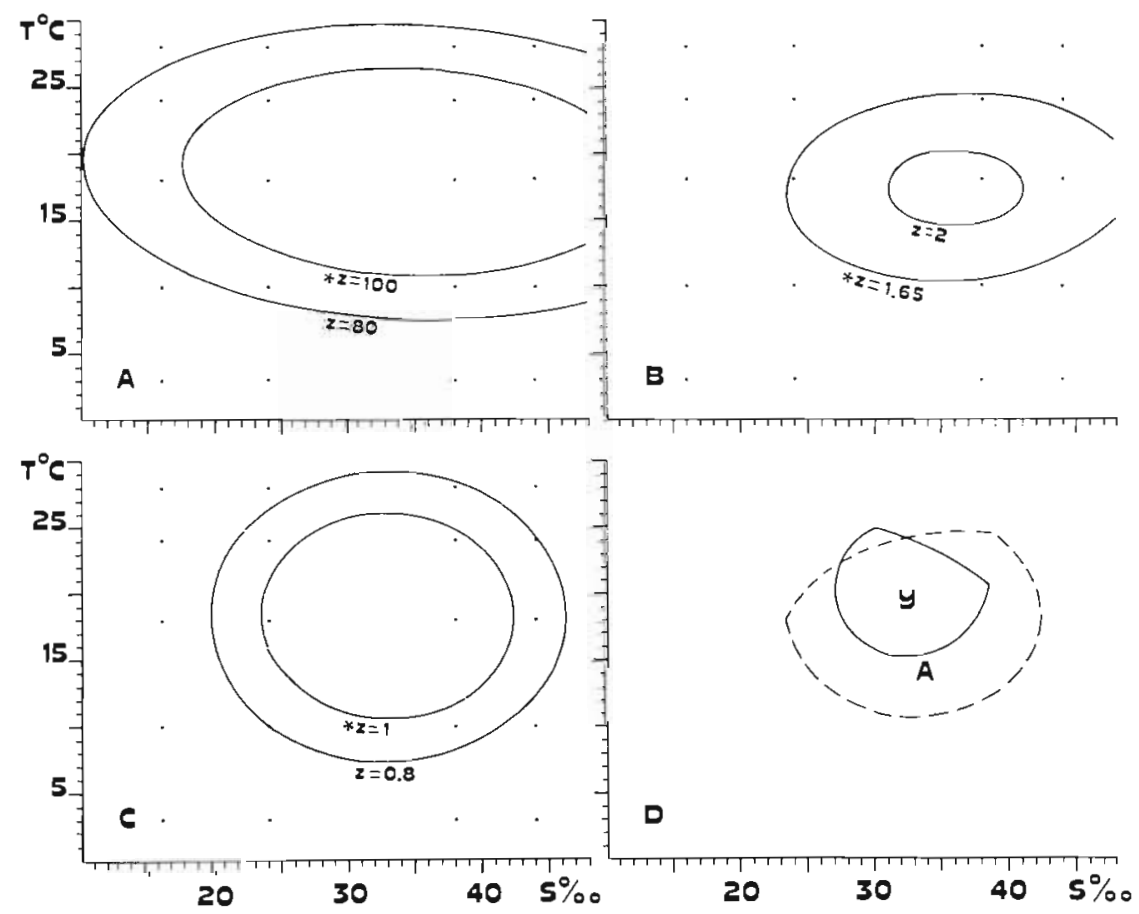

Fig. 4. Botryllus schlosseri. Response surfaces for adult colonies. A: Percentage of survival $\left(z=\sin ^{2}-1.413+0.199 T+0.079 S-\right.$ $\left.0.005 T^{2}-0.001 S^{2}-0.0004 T S ; F_{16 / 5}=1.41\right)$. B: Index of colonial growth $\left(z=-3.38+0.27 T+0.17 S-0.008 T^{2}-0.002 S^{2}+\right.$ $\left.0.0007 \mathrm{TS} ; F_{5 / 366}=134\right)$. C: Index of quality of life $\left(z=-2.40+0.12 T+0.15 S-0.003 T^{2}-0.002 S^{2}-0.00001 T S_{i} F_{5 / 391}=\right.$ 23.43). D: Intersections of optimal areas of colonial-growth index and quality-of-life index for young colonies (solid line) and adult colonies (broken line) 
of-generation stage; only a slow circulation indicated that they were still alive.

At $10^{\circ} \mathrm{C}$, hibernation occurred in samples kept in 24 $\mathrm{S}$ and $44 \% \mathrm{~S}$, but not in colonies kept in $38 \% \mathrm{~S}$. After $15 \mathrm{~d}$ of treatment we subdivided the latter sample into two sub-samples, each consisting of 10 colonies. One of them was kept at $10^{\circ} \mathrm{C}$, the other brought to a temperature of $6{ }^{\circ} \mathrm{C}$; all colonies of the latter underwent hibernation within $10 \mathrm{~d}$.

\section{Data Processing}

The F ratios show a sufficiently good fitting of interpolating functions, with the exception of those referring to the percentages of survival. This is quite under- standable because of the relatively few experimental points of the latter.

\section{Percentage of Survival}

Botryllus schlosseri. In both young and adult colonies (Figs 3A and 4A), but especially in adult ones, this parameter seems to be more heavily influenced by temperature than by salinity. The optimal area for young colonies is almost half of that referring to adult colonies.

Botrylloides leachi. We omitted the response surfaces referring to the percentage of survival because of the presence of hybernating and regressing colonies. Both phenomena, even though principally reversible,

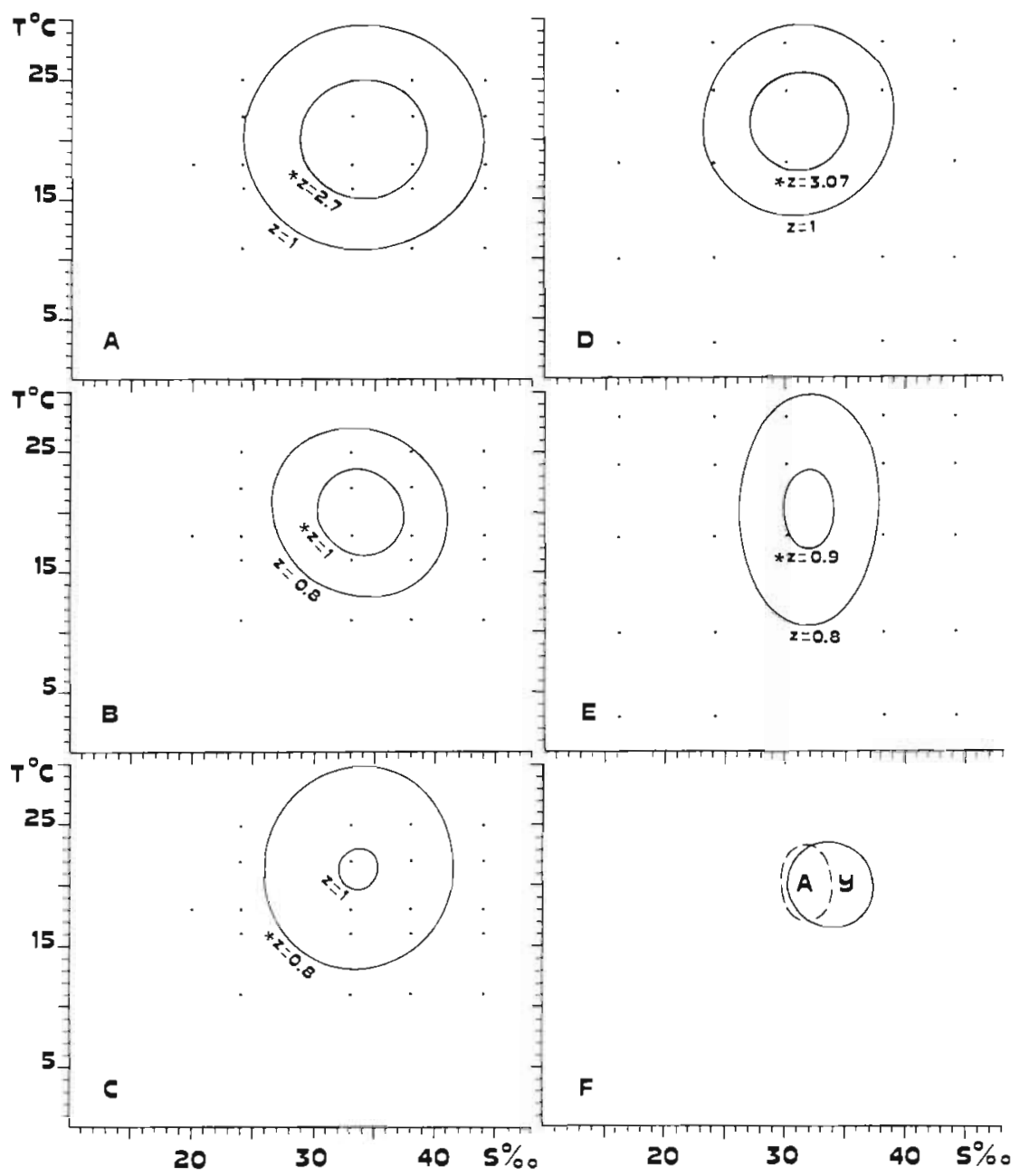

Fig. 5. Botrylloides leachi. Response surfaces. A: Index of colonial growth for young colonies $(z=-0.003+1.10 T+1.64 S-0.03$ $\left.T^{2}-0.02 S^{2}+0.005 T S ; F_{S / 307}=53\right)$. B: Index of quality of life for young colonies $\left(z=-7.49+0.24 T+0.36 S-0.005 T^{2}-\right.$ $\left.0.005 S^{2}-0.001 T S_{i} F_{5 / 327}=28.3\right)$. C: Mean length $(\mathrm{mm})$ of zooids for young colonies $\left(z=-4.12+0.12 T+0.23 S-0.003 T^{2}-\right.$ $\left.0.003 S^{2}+0.0002 T S ; F_{5 / 283}=49.5\right)$. D: Index of colonial growth for adult colonies $\left(z=-57.68+1.74 T+2.76 S-0.04 T^{2}-0.04\right.$ $\left.S^{2}+0.004 T S_{i} F_{5 / 153}=23.3\right)$. E: Index of quality of life for adult colonies $\left(z=-2.95+0.04 T+0.22 S-0.001 T^{2}-0.003 S^{2}+\right.$ $\left.0.0001 T S_{;} F_{5 / 455}=31.3\right)$. F: Intersections of optimal areas of colonial-growth index and of quality-of-life index for young colonies (solid line) and adult colonies (broken line) 
lead to lethality after a certain time. On the other hand, by considering colonies which exhibit hybernation or regression as living, the optimal area would become hyperbolic with no biological meaning.

Tables 4 and 5 indicate that high temperatures are better tolerated in combination with intermediate salinities (more pronouncedly so by young colonies), and high salinities in combination with intermediatelow temperatures. Table 5 shows further the dependence of hybernation temperature on salinity.

\section{Index of Colonial Growth}

Botryllus schlosseri. In young colonies (Fig. 3B) the slope of about -1 of the major axis of the ellipses shows a strong interaction factor between temperature and salinity; high salinities are tolerated in combination with low temperatures and vice versa.

In adult colonies (Fig. 4B), growth seems to be more heavily influenced by temperature.

Botrylloides leachi. The optimal area has an almost circular form in both experimental series. That of young colonies is a bit wider than that referring to adult colonies, but the values of the parameter are higher in the latter (Fig. 5A-D).

\section{Index of Quality of Life}

Botryllus schlosseri. Temperature exerts an influence that seems to slightly exceed that of salinity. The optimal area for young colonies (Fig. 3C) is about $50 \%$ of that referring to adult colonies (Fig. 4C).

Botrylloides leachi. While in young colonies (Fig. $5 \mathrm{~B}$ ) the optimal area is approximately circular, indicating an equal influence of temperature and salinity, in adult colonies (Fig. 5E) the optimal area appears to be more heavily influenced by salinity than by temperature. The optimal area for adult colonies is practically reduced to a point; for this reason we rated the area corresponding to $z \geqslant 0.9$.

\section{Mean Length of Zooids (Young Colonies Only)}

Botryllus schlosseri. This parameter seems to be strongly influenced by temperature. The optimal area (Fig. 3D) shows a pronounced tolerance to salinity at temperatures above $11^{\circ} \mathrm{C}$.

Botrylloides leachi. The optimal area has a circular form (Fig. 5C) and is contained in the optimal area referring to the index of colonial growth.

Table 6. Botryllus schlosseri and Botrylloides leachi. Squared canonical correlation between quality-of-life categories (indicated by letters). 'Rank correlation test' (Kendall, 1948; Armitage, 1955) on contingency tables (values above 0.4) rejected the null hypothesis of no correlation at the significance level of 0.001 for $B$. schlosseri and of 0.05 for $B$. leach $i$

\begin{tabular}{|c|c|c|c|c|c|c|c|c|c|c|c|}
\hline \multirow{2}{*}{\multicolumn{12}{|c|}{ Botryllus schlosseri }} \\
\hline \multicolumn{5}{|c|}{ Young colonies (total number of samples 123) } & & & & & & & \\
\hline & I & $\mathrm{H}$ & $\mathrm{G}$ & F & $E$ & D & C & B & & & \\
\hline A & 0.03 & 0.29 & 0.22 & 0.23 & 0.34 & 0.07 & 0.11 & 0.45 & & & \\
\hline B & 0.08 & 0.57 & 0.42 & 0.30 & 0.36 & 0.17 & 0.22 & & & 0.46 & $\mathrm{H}$ \\
\hline C & 0.37 & 0.31 & 0.31 & 0.16 & 0.57 & 0.21 & & & 0.80 & 0.41 & G \\
\hline $\mathrm{D}$ & 0.09 & 0.11 & 0.14 & 0.08 & 0.35 & & & 0.38 & 0.57 & 0.07 & $F$ \\
\hline$E$ & 0.39 & 0.40 & 0.32 & 0.32 & & & 0.69 & 0.64 & 0.83 & 0.27 & $\mathrm{E}$ \\
\hline$F$ & 0.03 & 0.23 & 0.24 & & & 0.13 & 0.07 & 0.11 & 0.23 & 0.08 & $\mathrm{D}$ \\
\hline$G$ & 0.15 & 0.35 & & & 0.11 & 0.65 & 0.38 & 0.71 & 0.85 & 0.32 & C \\
\hline \multirow[t]{4}{*}{$\mathrm{H}$} & 0.16 & & & 0.24 & 0.21 & 0.44 & 0.41 & 0.41 & 0.52 & 0.09 & B \\
\hline & & & 0.55 & 0.48 & 0.06 & 0.67 & 0.53 & 0.47 & 0.74 & 0.07 & A \\
\hline & & & B & $\mathrm{C}$ & $\mathrm{D}$ & $\mathrm{E}$ & $\mathrm{F}$ & G & $\mathrm{H}$ & I & \\
\hline & & & & & & & \multicolumn{5}{|c|}{ Adult colonies (total number of samples 111) } \\
\hline \multicolumn{12}{|c|}{ Botrylloides leachi } \\
\hline \multicolumn{12}{|c|}{ Young colonies (total number of samples 101) } \\
\hline & I & $\mathrm{H}$ & $\mathrm{G}$ & $\mathrm{F}$ & E & $\mathrm{D}$ & C & B & & & \\
\hline A & 0.38 & 0.39 & 0.05 & 0.25 & 0.25 & 0.38 & 0.34 & 0.37 & & & \\
\hline $\mathrm{B}$ & 0.20 & 0.45 & 0.06 & 0.31 & 0.31 & 0.44 & 0.36 & & & 0.00 & $\mathrm{H}$ \\
\hline $\mathrm{C}$ & 0.49 & 0.24 & 0.07 & 0.45 & 0.49 & 0.83 & & & 0.07 & 0.00 & G \\
\hline $\mathrm{D}$ & 0.57 & 0.35 & 0.08 & 0.41 & 0.43 & & & 0.34 & 0.51 & 0.00 & $\mathrm{~F}$ \\
\hline $\mathrm{E}$ & 0.16 & 0.69 & 0.17 & 0.25 & & & 0.26 & 0.06 & 0.63 & 0.00 & $\mathrm{E}$ \\
\hline $\mathrm{F}$ & 0.28 & 0.42 & 0.24 & & & 0.11 & 0.47 & 0.05 & 0.12 & 0.00 & $\mathrm{D}$ \\
\hline $\mathrm{G}$ & 0.12 & 0.58 & & & 0.03 & 0.04 & 0.49 & 0.02 & 0.05 & 0.00 & $\mathrm{C}$ \\
\hline \multirow[t]{4}{*}{$\mathrm{H}$} & 0.41 & & & 0.10 & 0.25 & 0.04 & 0.51 & 0.20 & 0.23 & 0.00 & B \\
\hline & & & 0.33 & 0.15 & 0.13 & 0.24 & 0.30 & 0.21 & 0.52 & 0.00 & A \\
\hline & & & B & C & $D$ & $E$ & $F$ & $\mathrm{G}$ & $\mathrm{H}$ & I & \\
\hline & & & & & & & \multicolumn{5}{|c|}{ Adult colonies (total number of samples 75} \\
\hline
\end{tabular}




\section{Squared Canonical Correlation}

Squared canonical correlations between quality-oflife categories are given in Table 6 , while the dependence of the latter on temperature and salinity is shown in Figures 6 and 7 (the plots were obtained by considering the percentages of appearence of the normal character under different environmental conditions).

Botryllus schlosseri. The obtained values show generally greater interaction between the categories referring to adult colonies than to young ones (Table 6), and only some fluctuations between these two sets of samples in what refers to their dependence on the environmental factors. Salinity exerts a more pronounced influence than temperature (Fig. 6).

Botrylloides leachi. A marked influence of salinity

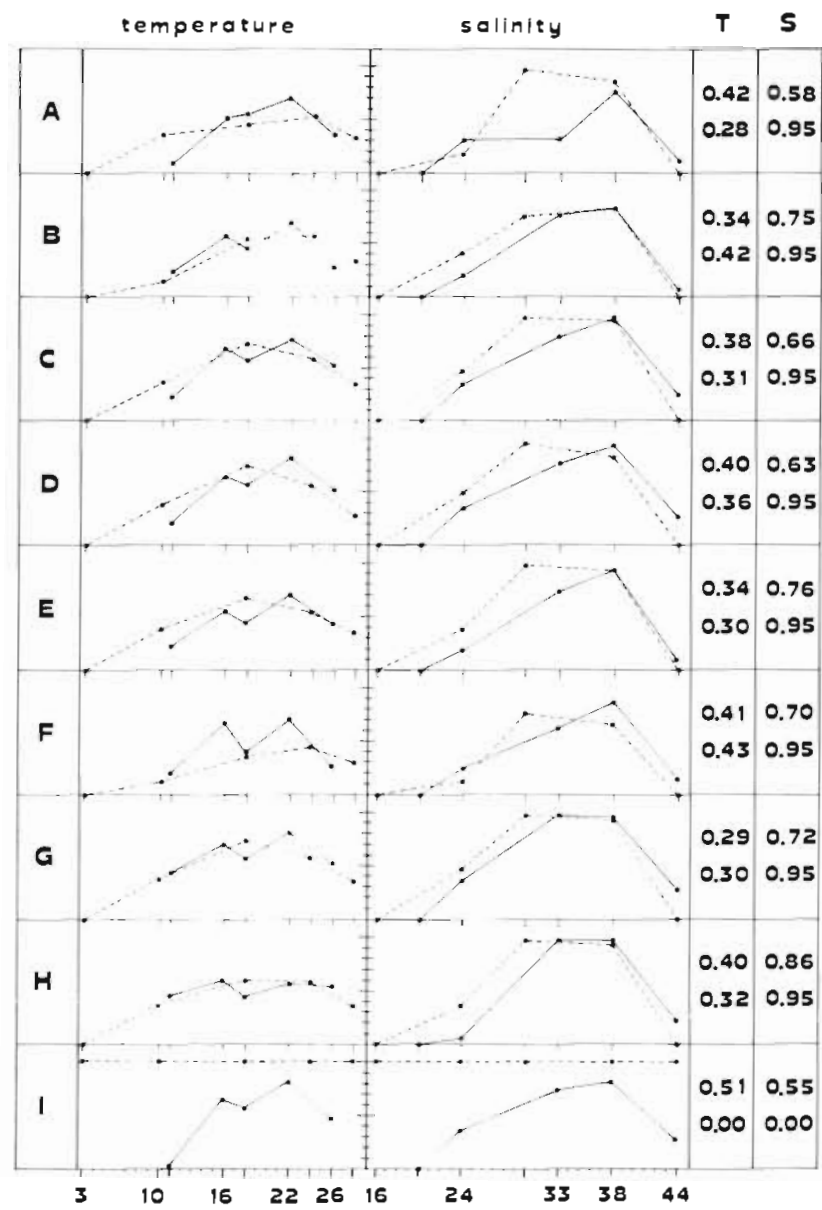

Fig. 6. Botryllus schlosseri. Percentage of appearence of normal character of categories related to quality of life, expressed as functions of temperature and salinity. Solid line: young colonies; total number 362 . Broken line: adult colonies; total number 396. Squared canonical correlations of categories with temperature ( $T$ ) and salinity (S). Upper numbers: young colonies; lower numbers: adult colonies. In order to allow comparison between young and adult colonies, the sample at $3^{\circ} \mathrm{C}$ has not been taken into account with respect to temperature is exhibited. This phenomenon is enhanced in adult colonies (Fig. 7); exception: Category I, which presents only the normal character in adult colonies.

\section{DISCUSSION}

\section{Botryllus schlosseri}

Comparison between young and adult colonies by means of optimal areas of survival and quality of life (Figs $3 \mathrm{~A}-\mathrm{C}$ and $4 \mathrm{~A}-\mathrm{C}$ ) reveals a greater tolerance of the adults to the environmental conditions considered. In both groups of colonies these areas are located above $11^{\circ} \mathrm{C}$, the lowest level of their thermal range for

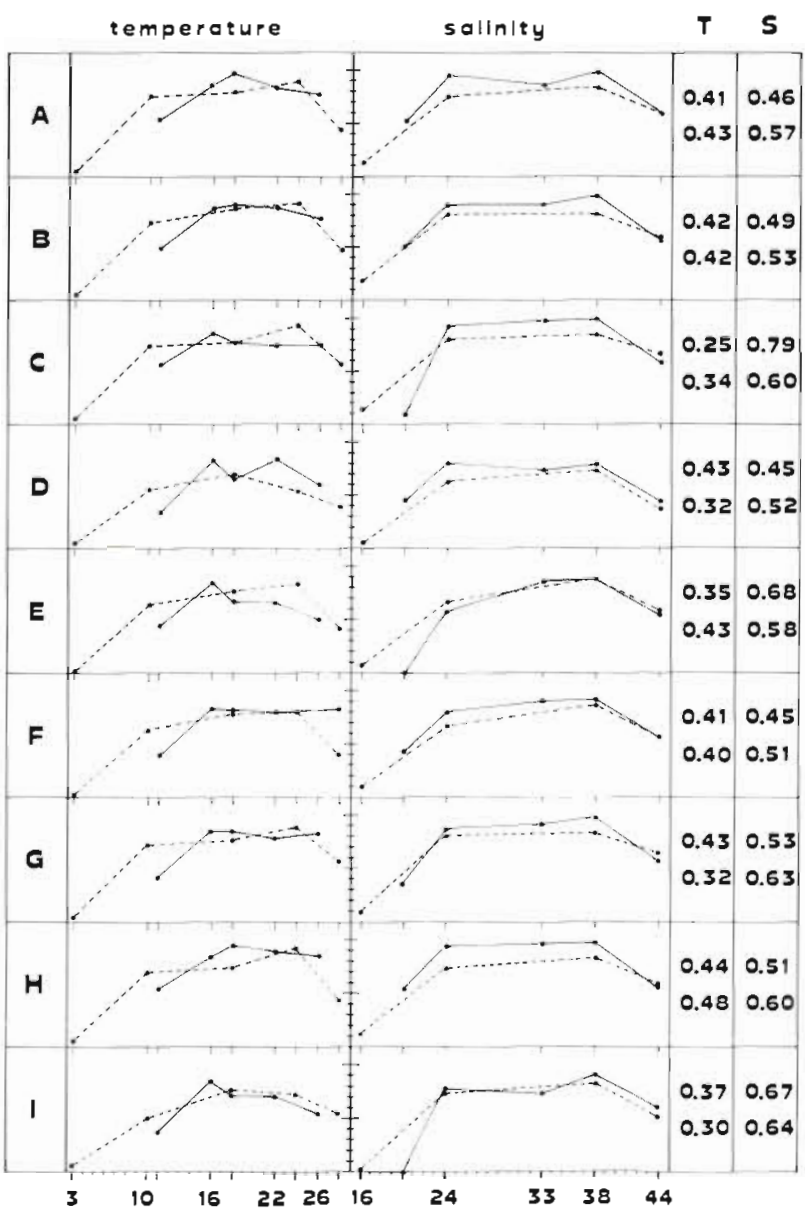

Fig. 7. Botrylloides leachi. Percentage of appearence of normal character of categories related to quality of life, expressed as functions of temperature and salinity. Solid line: young colonies; total number 333. Broken line: adult colonies; total number 341. Squared canonical correlations of categories with temperature (T) and salinity (S). Upper numbers: young colonies; lower numbers: adult colonies. In order to allow comparison between young and adult colonies, the sample at $3^{\circ} \mathrm{C}$ has not been taken into account 
sexual reproduction in the Venetian Lagoon (Sabbadin, 1955a; Brunetti, 1974). The highest thermal level in the optimal areas under consideration is $26^{\circ} \mathrm{C}$; this corresponds to the mean temperature of the outgoing tide in the Venetian Lagoon during July and August (Brunetti and Canzonier, 1973; Brunetti et al., 1977.) Exceptionally this value is exceeded, on some days, for a few hours only.

The centers of optimal areas are in correspondence with a salinity of $33 \%$, which constitues the mean annual value of Lagoon waters. The salinity range of the optimal areas, and especially that for adult colonies, is wider than we observed experimentally in the Lagoon.

Thus we can say that the behaviour of young colonies is similar to that of adult ones in regard to survival and quality of life, whith the exception that the optimal area of adult colonies is wider than that of young colonies.

On the contrary, response surfaces of the index of colonial growth are very different (Figs $3 \mathrm{~B}$ and $4 \mathrm{~B}$ ). The values referring to young colonies are much higher; that was forseeable, because the highest rates of blastogenetic growth occur between the 3rd and the 5th generation (Brunetti and Copello, 1978).

Major diversification occurs by disposition of contour lines. In adult colonies the optimal area of the index of colonial growth (Fig. 4B) has a shape similar to that referring to the percentage of survival (Fig. 4A) and the index of quality of life (Fig. 4C); it overlaps with them: the center is shifted toward higher salinities $(36-38 \%)$. On the contrary, the optimal area of the index of colonial growth of young colonies (Fig. 3B) extends very much beyond the optimal zone referring to survival and quality of life (Fig. 3A-C). Lack of experimental samples of young colonies below $10^{\circ} \mathrm{C}$ makes our interpolation not very reliable (for instance, the optimal area extended beyond $0^{\circ} \mathrm{C}$ is absurd); anyway the response surface retains an informative value by indicating the tendency of the phenomenon, which is characterized by strong interaction between temperature and salinity of the type high-low.

This fact has, in our opinion, a precise biological meaning. It is useful for young settlers to have a wide optimal growth area and to tolerate many different combinations of temperature and salinity; this results in a high competitive capacity, even under extreme hydrological conditions.

Interaction between temperature and salinity of the type high-low tends to protect the first and the last generations, which are generated, respectively, in April and November (Brunetti, 1974). The larvae generated during spring find themselves in sea waters with increasing temperature and decreasing salinity, while larvae born in autumn are exposed to decreasing temperatures, but high salinities (Brunetti and Canzonier, 1973; Brunetti et al., 1977).

If we consider now the intersection between optimal areas of colonial growth and quality of life for young and adult colonies (Fig. 4D) we notice that they are almost concentric. This figure, which synthesizes our experimental results, clearly shows the greater 'survival ability' of adult colonies with respect to temperature and salinity.

Two morphological aspects, which have been taken into consideration in constructing the index of quality of life, could be interesting. The first one is the structural simplification of zooids which we found at $16 \%$ $S$ : it seems that this phenomenon could be an example of 'brackish-water pauperization' (Kinne, 1964). The second one is colonial degeneration which manifested itself as irreversible, i. e. lethal (at the end of the experiment we maintained colonies in breeding conditions for about 2 months and could thus observe this fact). The ratio of colonial degeneration was very high in $16 \% \mathrm{~S}$ (Table 2); we did not take this into account when evaluating the response surface of the percentage of survival in adult colonies (Fig. 4A).

In conclusion, the colonial Ascidia Botryllus schlosseri seems to be sufficiently eurytherm and euryhaline, and perfectly adapted to a coastal, but not properly estuarine environment. This agrees with the distribution of this species in the Venetian Lagoon (Brunetti and Menin, 1977), which has almost completely lost its estuarine character, and with its distribution in the fjords of Norway (Dybern, 1969).

\section{Botrylloides leachi}

The intersections of optimal areas of the index of colonial growth and of the index of quality of life in both young and adult colonies (Fig. $5 \mathrm{~F}$ ) show a thermal range from $17^{\circ}$ to $24^{\circ} \mathrm{C}$. This range coincides with that of sexual reproduction of the species (Brunetti, 1976). On the contrary, the salinity range of young colonies ( 30 to $38 \%$ S) is wider than that of adult ones (30 to $34 \%$ S). Considering now colonial growth, no substantial difference exists between young and adult colonies (Fig. 5A-D), even though the area of 'positive growth' is wider in young colonies.

Salinity reveals itself as the dominant controlling factor only in regard to the index of quality of life for adult colonies (Fig. 5E); an interaction of the type highlow exists between salinity and temperature. In the remaining cases salinity and temperature appear to exert the same influence, with a low interactive factor.

Also hibernation seems to be favoured by interaction between temperature and salinity of the type high-low (Table 5). 


\section{Comparison Between Botryllus schlosseri and Botrylloides leachi}

Botrylloides leachi seems to be less eurytherm and less euryhaline than Botryllus schlosseri. The stronger dependence of $B$. leachi on salinity is confirmed by squared canonical correlation (Figs 6, 7). Moreover, the optimal areas of the quality-of-life index for young and adult colonies of $B$. leachi (Fig. 5B-E) are both contained in the corresponding areas of $B$. schlosseri, while those referring to the index of colonial growth of the former are for the most part contained in the corresponding ones of $B$. schlosseri (Figs $3 C$ and $4 C$ ). In regard to mean length of zooids, in $B$. schlosseri the dominant control factor is temperature, while in $B$. leachi temperature is only slightly dominant with respect to salinity.

When evaluating these results we must not forget possible influences of acclimatization. These have not been studied by us.

Acknowledgements. This work was carried out at the Stazione Idrobiologica di Chioggia (University of Padua). We are grateful to the Director, Professor A. Sabbadin, and to Mr. L. Chiereghin for help. Our data were processed on Computer C.D.C. Cyber 7006 of the Centro di Calcolo Scientifico (University of Padua). Our studies were supported by a C.N.R. grant from the Istituto di Biologia del Mare, Venice.

\section{LITERATURE CITED}

Alderdice, D. F. (1972). Factor combinations. Responses of marine poikilotherms to environmental factors acting in concert. In: Kinne, O. (ed.) Marine ecology, Vol. I, Part 3. Wiley, London, pp. 1659-1722

Anderberg, M. R. (1973). Cluster analysis for application, Academic Press, New York

Armitage, P. (1955). Tests for linear trends in proportions and frequencies. Biometrics 11: 375-385

Berrill, N. J. (1941). The development of the bud in Botryllus Biol. Bull. mar, biol. Lab., Woods Hole 80: 169-184

Berrill, N. J. (1947). The developmental cycle of Botrylloides. Q. Jl microsc. Sci. 88: 393-407

Box, G. E. P. (1954). The exploration and exploitation of response surfaces: some general consideration and examples. Biometrics 10: 16-60

Box, G. E. P., Youle, P. V. (1955). The exploration and exploitation of response surfaces: an example of the link between the fitted surface and the basic mechanism of the system. Biometrics 11: 287-323

Brett, J. R. (1970). Temperature: animals: fishes: functional responses. In: Kinne, O. (ed.) Marine ecology, Vol. I, Part 1. Wiley, London, pp. 515-560

Brunetti, R. (1974). Observations on the life cycle of Botryllus schlosseri (Pallas) (Ascidiacea) in the Venetian Lagoon. Boll. Zool. 41: 225-251
Brunetti, R. (1976). Biological cycle of Botrylloides leachi (Savigny) (Ascidiacea) in the Venetian Lagoon. Vie Milieu 26: 105-122

Brunetti, R. (1979). Ascidians of the Venice Lagoon. I. Annotated Inventory of species. Ann. Inst. océanogr., Paris 55: 95-109

Brunetti, R., Burighel, P. (1969). Sviluppo dell'apparato vascolare in Botryllus schlosseri (Pallas). Pubbl. Staz. zool. Napoli $37\left(2^{\circ}\right.$ suppl.): $137-148$

Brunetti, R., Canzonier, J. W. (1973). Physico-chemical observations on the waters of the southern basin of the Laguna Veneta from 1971 to 1973. Atti Ist. veneto Sci. 131: 503-523

Brunetti. R., Copello, M. (1978). Growth and senescence in colonies of Botryllus schlosseri (Pallas) (Ascidiacea). Boll. Zool. 45: 359-364

Brunetti, R., Menin, F. (1977). Ascidians of the Laguna Veneta. II. Distribution and ecological observations. Boll Zool. 44: 337-352

Brunetti, R., Menin, F., Canzonier, J. W. (1977). Physicochemical parameters of water of the lower basin of the Laguna Veneta for 1973-74. Riv. Idrobiol. 16: 173-197

Burighel, P., Brunetti, R. (1971). The circulatory system in the blastozooid of the colonial ascidian Botryllus schlosseri (Pallas). Boll. Zool. 38: 273-289

Burighel, P., Brunetti, R., Zaniolo, G. (1976). Hibernation of the colonial ascidian Botrylloides leachi (Savigny): Histological observations. Boll. Zool. 43: 293-301

Dybern, B. I. (1969). Distribution and ecology of Ascidians in Kvituzdvikpollen and Vågsbopollen on the west coast of Norway. Sarsia 37: 21-40

Feinstein, A. R. (1975). Statistical models and medical reality. In: Gupta, R. R. P. (ed.) Proceeding of the conference on applied statistics, Halifax 1974. North-Holland, Amsterdam, pp. 41-65

Garside, E. T. (1970). Temperature: animals: fishes: structural responses. In: Kinne, O. (ed.) Marine ecology, Vol. I, Part 1. Wiley, London, pp. 561-616

Holliday, F. G. T. (1971). Salinity: animals: fishes. In: Kinne, O. (ed.) Marine ecology, Vol. I, Part 2. Wiley, London, pp. 997-1083

Kendall, M. G. (1948). Rank correlation methods, Griffin London

Kinne, O. (1964). The effects of temperature and salinity on marine and brackish water animals. I. Salinity and temperature-salinity combinations. Oceanogr. mar. Biol. A Rev. 2: 281-339

Kinne, O. (1970). Temperature: animals: invertebrates. In: Kinne, O. (ed.) Marine ecology, Vol. I, Environmental factors, Part 1. Wiley, London, pp. 407-514

Kinne, O. (1971). Salinity: animals: invertebrates. In: Kinne, O. (ed.) Marine ecology, Vol. I, Environmental factors, Part 2. Wiley, London, pp. 821-995

Mukai, H., Sugimoto, K., Taneda, Y. (1978). Comparative studies on the circulatory system of the compound Ascidians, Botryllus, Botrylloides and Symplegma. J. Morph. 157: $49-78$

Sabbadin, A. (1955a). Il ciclo biologico di Botryllus schlosseri (Pallas) (Ascidiacea) nella Laguna di Venezia. Archo. Oceanogr. Limnol. 10: 217-230

Sabbadin, A. (1955b). Osservazioni sullo sviluppo, l'accrescimento e la riproduzione di Botryllus schlosseri (Pallas) in condizioni di laboratorio. Boll. Zool. 22: 243-263

Williams, E. J. (1952). Use of scores for the analysis of association in contingency tables. Biometrika 39: 274-289 